\title{
Protective effects of Semen Crotonis Pulveratum on trinitrobenzene sulphonic acid-induced colitis in rats and $\mathrm{H}_{2} \mathrm{O}_{2}$-induced intestinal cell apoptosis in vitro
}

\author{
XIAOHONG WANG ${ }^{1}$, JIE ZHAO ${ }^{2}$, ZHE HAN $^{2}$ and FANG TANG ${ }^{1}$ \\ ${ }^{1}$ Tianjin Medical University General Hospital, Tianjin 300052; \\ ${ }^{2}$ Basic Medical College, Tianjin Medical University, Tianjin 300070, P.R. China
}

Received October 21, 2014; Accepted March 19, 2015

DOI: $10.3892 / \mathrm{ijmm} .2015 .2175$

\begin{abstract}
Ulcerative colitis (UC) is a chronic inflammatory bowel disease. Semen Crotonis Pulveratum (SCP) has been used as a traditional medicine for the treatment of UC. However, its molecular mechanisms of action have not yet been elucidated. In the present study, we aimed to investigate the preliminary mechanisms of the role of SCP on trinitrobenzene sulphonic acid (TNBS)-induced UC in rats and hydrogen peroxide $\left(\mathrm{H}_{2} \mathrm{O}_{2}\right)$ induced intestinal cell apoptosis in vitro. Wistar rats $(\mathrm{n}=9$ per group) were randomly divided into 4 groups: the normal control group, the UC group, the UC + SCP group and the $\mathrm{UC}+$ sulfasalazine group as a positive control. The proportion of $\mathrm{CD}^{+}{ }^{+} \mathrm{CD} 25^{+} \mathrm{T}$ cells and $\mathrm{CD} 4{ }^{+} \mathrm{CD} 25^{+} \mathrm{Foxp} 3^{+}$Tregs, and the expression levels of interleukin (IL)-6 and IL-10 in the peripheral blood, as well as the expression levels of cyclooxygenase-2 (COX-2) and intercellular adhesion molecule-1 (ICAM-1) in the colon tissues were determined by flow cytometry, ELISA and immunohistochemical staining, respectively. Rat intestinal epithelial (IEC-6) cell apoptosis induced by $\mathrm{H}_{2} \mathrm{O}_{2}$ was determined by TUNEL assay, flow cytometry using Annexin V/ propidium iodide (PI) staining and western blot analysis of caspase-3 activation, respectively. Significantly higher proportions of circulating $\mathrm{CD} 4^{+} \mathrm{CD} 25^{+} \mathrm{T}$ cells and $\mathrm{CD} 4^{+} \mathrm{CD} 25^{+} \mathrm{Foxp} 3^{+}$ Tregs were present in the UC + SCP group compared with the UC group. A significantly decreased expression of IL-6 and an increased expression of IL-10 were also observed in the $\mathrm{UC}+\mathrm{SCP}$ group compared with UC group. SCP significantly reduced the UC-induced increase in the expression of COX-2 and ICAM-1 in the colon tissues. SCP inhibited cell apoptosis and caspase- 3 activation induced by $\mathrm{H}_{2} \mathrm{O}_{2}$ in the ICE- 6 cells. Our data thus indicate that SCP inhibits inflammation in UC by
\end{abstract}

Correspondence to: Dr Fang Tang, Tianjin Medical University General Hospital, 154 Anshan Road, Heping, Tianjin 300052, P.R. China

E-mail: medsciwxh@126.com

Key words: Semen Crotonis Pulveratum, ulcerative colitis, apoptosis, regulatory $\mathrm{T}$ cells, cyclooxygenase-2, intercellular adhesion molecule-1 increasing the proportion of circulating Tregs, altering cytokine production and decreasing COX-2 and ICAM-1 expression. In addition it protects against $\mathrm{H}_{2} \mathrm{O}_{2}$-induced intestinal cell apoptosis in vitro.

\section{Introduction}

Ulcerative colitis (UC) is a chronic inflammatory condition of the gastrointestinal tract and is a type of inflammatory bowel disease (IBD). The incidence of UC has been reported to be approximately $10-20$ cases per 100,000 populations each year in Western countries (1). Although the etiology of UC remains largely unknown, an involvement of local immune reactions and intestinal cell apoptosis has been suggested (2,3).

Local immune reactions in UC refer to the activation of the mucosal immune system in response to commensal luminal bacterial antigens along with imbalance in the function of regulatory $\mathrm{T}$ cells (Tregs), pathological cytokine production and abnormal protein expression. Intercellular adhesion molecule-1 (ICAM-1) belongs to the immunoglobulin superfamily. It can bind to lymphocyte function-associated antigen-1 on leukocytes and induces the inflammatory reaction, cell apoptosis and other immune responses. ICAM-1 participates in the adhesion between leukocytes and vascular endothelial cells and is closely associated with leukocyte transmigration and inflammation (4). In UC, a significant elevation in the colonic levels of cyclooxygenase-2 (COX-2) and ICAM-1 has been reported $(5,6)$.

Immunosuppressive cytokines, such as transforming growth factor- $\beta$ and interleukin (IL)-10 have been implicated in $\mathrm{CD}^{+}{ }^{+} \mathrm{CD} 25^{+} \mathrm{T}$ cell function (7). The IL-10 is primarily produced by monocytes and to a lesser extent, by $\mathrm{CD} 4{ }^{+} \mathrm{CD} 25^{+} \mathrm{Foxp}^{+} \mathrm{T}$ cells. It has been demonstrated that IL-10 knockout mice develop IBD under conventional conditions, suggesting the importance of IL-10 in the regulation of intestinal inflammation (8). The immunoregulatory activity of IL-10 is based upon its ability to inhibit both cytokine synthesis and antigen presentation (9). Thus, IL-10 downregulates the major histocompatibility complex class II and co stimulatory molecule expression that is required by antigen-presenting cells in their activation of T cells. Additionally, IL-10 inhibits the synthesis of a vast array of macrophage-derived cytokines that play a crucial role in inflammation, such as IL-1, IL-6, IL-12, 
interferon $\alpha$, tumor necrosis factor- $\alpha(\mathrm{TNF}-\alpha)$ and the chemokine, IL-8. Finally, IL-10 could enable the immunosuppressive action by inducing the production of cytokine inhibitors such as IL-1 receptor antagonist and soluble TNF- $\alpha$ receptors $(10,11)$.

On a different note, IL- 6 is secreted by $\mathrm{T}$ cells and macrophages to induce the immune response, leading to inflammation (12). IL-6 signals through a cell-surface type I cytokine receptor complex consisting of the ligand-binding IL-6R $\alpha$ chain and the signal-transducing component glycoprotein 130 . IL-6 interacts with its receptor to initiate a signal transduction cascade, leading to the activation of transcription factors, Janus kinase 2 and signal transducers and activators of transcription (STATs) (13).

Sulfasalazine (SFZ), 5-aminosalicilic acid and glucocorticosteroids have been used in the treatment of UC (14-18). The goal is to rapidly induce the remission of symptoms and mucosal inflammation; however, the associated adverse effects restrict their application (19-22). Previously, traditional Chinese medicines, such as Semen Crotonis Pulveratum (SCP) have been used for years in the treatment of UC and have been shown to be effective in clinical settings (23). SCP is the main component of croton seeds, which have potential anti-inflammatory, analgesic and antibacterial properties (23). However, the molecular mechanisms of action of this drug in the treatment of UC remain unknown.

In the present study, the mechanisms of action of SCP in the treatment of UC, including its effects on local immune reactions in trinitrobenzene sulphonic acid (TNBS)-induced colitis in rats and intestinal cell apoptosis induced by hydrogen peroxide $\left(\mathrm{H}_{2} \mathrm{O}_{2}\right)$ in vitro were investigated. Based on the results of the present study, it was concluded that SCP inhibits inflammation in UC by increasing the proportion of circulating Tregs, altering cytokine production and decreasing COX-2 and ICAM-1 expression. In addition, it protects against $\mathrm{H}_{2} \mathrm{O}_{2}$-induced intestinal cell apoptosis in vitro.

\section{Materials and methods}

Preparation of SCP. SCP was obtained from Tianjin Lerentang Pharmaceutical Co., Ltd., Tianjin, China. The extract of SCP was prepared by decocting the roasted croton seeds with boiling distilled water $(100 \mathrm{~g} / \mathrm{l})$ for approximately $3 \mathrm{~h}$, according to Chinese Pharmacopoeia (2005) (24). The decoction was filtered, lyophilized and stored at $4^{\circ} \mathrm{C}$. Dilutions were made using normal saline and filtered through a $0.22-\mathrm{mm}$ syringe filter.

Animals. Wistar rats ( $\mathrm{n}=36$; weighing 180-220 g; female) were purchased from the Institute of Laboratory Animal Science, Chinese Academy of Medical Sciences and Peking Union Medical College, Beijing, China. The rats were fed a standard laboratory diet and distilled water ad libitum and kept in an environment of $22 \pm 2^{\circ} \mathrm{C}$. All animal experiments were performed in strict accordance with the institutional and national animal ethics committee guidelines for the care and use of laboratory animals. All procedures and animal experiments were approved by the Animal Care and Use Committee of the Tianjin Medical University General Hospital, Tianjin, China.

Rat model of UC. UC was induced in the rats by the administration of TNBS $(100 \mathrm{mg} / \mathrm{kg})$ dissolved in $50 \%$ alcohol by oral gavage, as previously described (25). The rats were randomly divided into the following 4 groups ( $n=9$ per group): i) the normal control group; ii) the UC model group; iii) the UC + SFZ (250 mg/tablet, lot no. 20051012; Shanghai Sunve Pharmaceutical Co., Ltd., Shanghai, China) positive control group; and iv) the UC + SCP group. The extract of SCP $(0.5 \mathrm{ml} / 100 \mathrm{~g}$; diluted at a concentration of $0.24 \mathrm{mg} / \mathrm{ml})$ was administered intragastrically 3 days after establishing the model of UC, while $1 \mathrm{ml}$ of SFZ $(1.6 \mathrm{mg} / \mathrm{ml})$ was administered to the positive control group by oral gavage. The normal control group and UC model group were administered intragastrically with normal saline $(0.5 \mathrm{ml})$. All animals received treatment once a day for 1 week. Seven days later, chloral hydrate $(5 \%)$ was administered peritoneally to anesthetize the rats. Blood and colon tissues were then collected.

Flow cytometric analysis of $C D 4^{+}, C D 4^{+} C D 25^{+} T$ cells, and $\mathrm{CD}^{+} \mathrm{CD} 25^{+} \mathrm{Foxp}^{+}$Tregs in peripheral blood. Blood was collected through the caudal vein prior to anesthetization. Mononuclear cells were separated, treated with Triton X-100 and then stained with fluorescein isothiocyanate (FITC)-conjugated anti-CD4 (Cat. no. 11-0040-81), phycoerythrin-conjugated antiCD25 (Cat. no. 12-0390-80) and allophycocyanin-conjugated anti-Foxp3 (Cat. no. 77-5775) antibodies (Becton-Dickinson, Franklin Lakes, NJ, USA). After staining, the cells were analyzed using an EPISC Elite Enhanced System Performance (ESP) flow cytometer.

Enzyme-linked immunosorbent assay (ELISA) of IL-6 and IL-10 in peripheral blood. IL-6 and IL-10 expression levels were measured using ELISA according to the manufacturer's instructions (RayBiotech, Inc., Norcross, GA, USA).

Immunohistochemical staining of COX-2 and ICAM-1 in colon tissues. Colon tissues embedded in paraffin blocks were cut into 5- $\mu \mathrm{m}$-thick sections, deparaffinized and treated with citrate buffer ( $\mathrm{pH}$ 6.0). They were then treated with $2 \%$ bovine serum albumin blocking buffer for $15 \mathrm{~min}$. The processed tissue sections were then incubated with primary antibodies against COX-2 (Cat. no. 4212-1; Epitomics, Burlingame, CA, USA) and ICAM-1 (Cat. no. 550302; Becton-Dickinson) overnight at $4^{\circ} \mathrm{C}$. Subsequently, the slides were treated for $30 \mathrm{~min}$ with goat anti-rabbit antibodies conjugated to horseradish peroxidase (HRP, for ICAM-1) or ChemMate ${ }^{\mathrm{TM}}$ EnVision + HRP (for COX-2) from EnVision ${ }^{\mathrm{TM}}$ Detection kit, peroxidase/DAB, rabbit/mouse (Cat. no. GK500705; Cell Signaling Technology, Danvers, MA, USA) and developed with 3,3'-diaminobenzidine. The tissue sections were then rinsed in distilled water and counterstained with hematoxylin for microscopic examination (Olympus BX51; Olympus America, Inc., Melville, NY, USA). Cells that were positive for ICAM-1 or COX-2 (brown color-stained cells) were quantified in 5 randomly selected fields at $\mathrm{x} 400$ magnification, and they were further scored as $0(<5 \%), 1(5-25 \%), 2(26-50 \%), 3(51-75 \%)$ and $4(>75 \%)$. The intensity of brown staining was scored as follows: 0 (no staining), 1 (weak), 2 (moderate) and 3 (strong staining). The above-mentioned 2 scores represented immunoreactivity.

Cell culture and treatment. Rat intestinal epithelial (IEC-6) cells were purchased from the American Type Culture Collection 
(ATCC, Manassas, VA, USA) and maintained in Roswell Park Memorial Institute-1640 medium (Life Technologies, Carlsbad, CA, USA) supplemented with $10 \%$ fetal bovine serum (HyClone, Waltham, MA, USA) at $37^{\circ} \mathrm{C}$ in a humidified incubator containing $5 \%$ carbon dioxide. The cells were divided into 4 groups as follows: i) the normal control group: untreated IEC- 6 cells; ii) the $\mathrm{H}_{2} \mathrm{O}_{2}$-treated group: IEC-6 cells treated with $\mathrm{H}_{2} \mathrm{O}_{2}(200 \mu \mathrm{l} / \mathrm{l})$ for $4 \mathrm{~h}$; iii) the $\mathrm{H}_{2} \mathrm{O}_{2}+\mathrm{SFZ}$ group: IEC- 6 cells treated with SFZ $(1.6 \mathrm{mg} / \mathrm{ml})$ for $24 \mathrm{~h}$ and then incubated with $\mathrm{H}_{2} \mathrm{O}_{2}(200 \mu \mathrm{l} / \mathrm{l})$ for $4 \mathrm{~h}$; and iv) the $\mathrm{H}_{2} \mathrm{O}_{2}+\mathrm{SCP}$ group: IEC- 6 cells treated with SCP $(0.25 \mathrm{mg} / \mathrm{ml})$ for $24 \mathrm{~h}$ and then incubated with $\mathrm{H}_{2} \mathrm{O}_{2}(200 \mu \mathrm{l} / \mathrm{l})$ for $4 \mathrm{~h}$.

In situ analysis of apoptosis using terminal deoxynucleotidyltransferase-mediated dUTP nick-end labeling (TUNEL) assay. The IEC- 6 cells $\left(4 \times 10^{4}\right.$ cells/well) were plated onto 6 -well plates with slides, and then treated with SFZ, SCP and $\mathrm{H}_{2} \mathrm{O}_{2}$ as mentioned above. After $4 \mathrm{~h}$ of treatment, the slides were treated with proteinase $\mathrm{K}(20 \mu \mathrm{g} / \mathrm{ml})$ for $5 \mathrm{~min}$ and stained using the TUNEL Apoptosis Detection kit (Merck, Darmstadt, Germany). The slides were visualized under an Eclipse 80i fluorescence microscope (Nikon, Tokyo, Japan) and representative images were captured. The number of apoptotic cells (green nuclear staining) and non-apoptotic cells (blue nuclear staining) in each slide was counted in 6 representative fields at x400 magnification by 2 independent observers blinded to the grouping.

Flow cytometric analysis of cell apoptosis. The IEC-6 cells were washed twice with phosphate-buffered saline, and stained with a mixture of FITC-labeled Annexin V (horizontal axis) and propidium iodide (PI) (vertical axis) (Annexin V-FITC Apoptosis Detection kit; KeyGen Biological Technology Development Co., Ltd., Nanjing, China). The cells were then analyzed using an EPISC Elite ESP flow cytometer (Beckman Coulter, Miami, FL, USA). Four different cell populations were identified using the flow cytometer: the viable population in the lower-left quadrant (low-PI and low-FITC signals), the early apoptotic population in the lower-right quadrant (low-PI and high-FITC signals), mechanically damaged cells in the upper-left quadrant (high-PI and low-FITC signals) and the late apoptotic or necrotic population in the upper-right quadrant (high-PI and high-FITC signals).

Western blot analysis of caspase-3 activation. The IEC-6 cells were lysed in $1 \mathrm{X}$ sodium dodecyl sulfate (SDS) cell lysis buffer (Tris-hydrochloride, $\mathrm{pH} 6.8 ; 2 \%$ SDS; and 10\% glycerol) and centrifuged at $12,000 \mathrm{rpm}$ for $30 \mathrm{~min}$ at $4{ }^{\circ} \mathrm{C}$. The protein from the supernatant liquid was quantified using bicinchoninic acid assay (BCA) (Pierce BCA Protein assay kit; Thermo Scientific, Waltham, MA, USA); $120 \mu \mathrm{g}$ protein were resolved by $10 \%$ SDS-polyacrylamide gel electrophoresis, transferred onto polyvinylidene fluoride membranes and blocked with $5 \%$ non-fat dry milk for $1 \mathrm{~h}$. The membranes were incubated with the primary antibodies [rabbit anti-rat primary antibody for procaspase-3 and activated caspase-3 (Cat. no. 9665S; Cell Signaling Technology), $\beta$-actin (Cat. no. sc-130300; Santa Cruz Biotechnology, Inc., Santa Cruz, CA, USA)] overnight at $4^{\circ} \mathrm{C}$ and then with the HRP-conjugated goat anti-rabbit secondary antibody (Cat. no. ZF-0516; Zhongshan Golden Bridge Biotechnology Co., Ltd., Beijing, China). Blots were developed using enhanced chemiluminescence reagent (Millipore, Billerica, MA, USA) and the signal intensity was quantified by densitometry using the Gel-Pro Analyzer 4.0 (Media Cybernetics, Inc., Bethesda, MD, USA). $\beta$-actin was used as a loading control.

Statistical analysis. Statistical analyses were performed using SPSS software, version 17.0 (SPSS, Inc., Chicago, IL, USA). All data are presented as the means \pm standard deviation (SD). The significance of differences among groups was determined using one-way analysis of variance with the least significant difference (LSD) test along with post-hoc analysis. A P-value of $<0.05$ was considered to indicate a statistically significant difference.

\section{Results}

Effect of SCP on the proportion of $C D 4^{+} C D 25^{+} T$ cells and $\mathrm{CD}^{+} \mathrm{CD} 25^{+} \mathrm{Foxp3}^{+}$Tregs in peripheral blood of rats with TNBS-induced colitis. Flow cytometry revealed significant higher proportions of $\mathrm{CD} 4{ }^{+} \mathrm{CD} 25^{+} \mathrm{T}$ cells and $\mathrm{CD} 4^{+} \mathrm{CD} 25^{+}$Foxp $^{+}$Tregs in the peripheral blood after a 7-day treatment with SCP compared with the UC model group. However, there was no significant difference observed in the total proportion of $\mathrm{CD}^{+}{ }^{+} \mathrm{T}$ cells among each group (Fig. 1).

Effect of SCP on the levels of IL-6 and IL-10 in peripheral blood of rats with TNBS-induced colitis. IL-6 expression was significantly increased in the UC model group compared with the normal group $(\mathrm{P}<0.01)$. A significant decrease in the expression of IL-6 was observed after 7 days of treatment with SCP compared with the UC group, while the expression level of IL-10 displayed the reverse profile (Fig. 2).

SCP treatment suppresses the expression of COX-2 and ICAM-1 in colon tissues of rats with TNBS-induced colitis. The induction of UC caused a significant increase in the colonic expression levels of COX-2 and ICAM-1 compared with the normal control group $(\mathrm{P}<0.05)$. Treatment with SCP significantly decreased the UC-induced increase in the expression of COX-2 and ICAM-1 (Fig. 3).

SCP inhibits $\mathrm{H}_{2} \mathrm{O}_{2}$ induced IEC-6 cell apoptosis. An increase in IEC-6 cell apoptosis was observed following treatment with $\mathrm{H}_{2} \mathrm{O}_{2}$ compared with the normal control group, while pretreatment with SCP resulted in a decrease in apoptosis (Fig. 4). After Annexin V-FITC and PI staining, flow cytometric analysis revealed that $12.92 \pm 4.52 \%$ of the $\mathrm{H}_{2} \mathrm{O}_{2}$-treated cells were late apoptotic or necrotic cells (Fig. 5), while pre-treatment with SCP resulted in a decrease $(1.42 \pm 0.18 \%)$. These results indicate that SCP inhibits the apoptosis of IEC- 6 cells induced by $\mathrm{H}_{2} \mathrm{O}_{2}$.

SCP inhibits the activation of caspase-3 induced by $\mathrm{H}_{2} \mathrm{O}_{2}$ in IEC-6 cells. The increased activation of caspase-3 was observed in the $\mathrm{H}_{2} \mathrm{O}_{2}$-treated control group as compared to the normal group. Following treatment with SCP, the expression of activated caspase-3 was significantly reduced, as shown by western blot analysis, and there was no significant difference observed between the SCP and SFZ groups. The expression levels of procaspase-3 displayed the reverse profile (Fig. 6). 

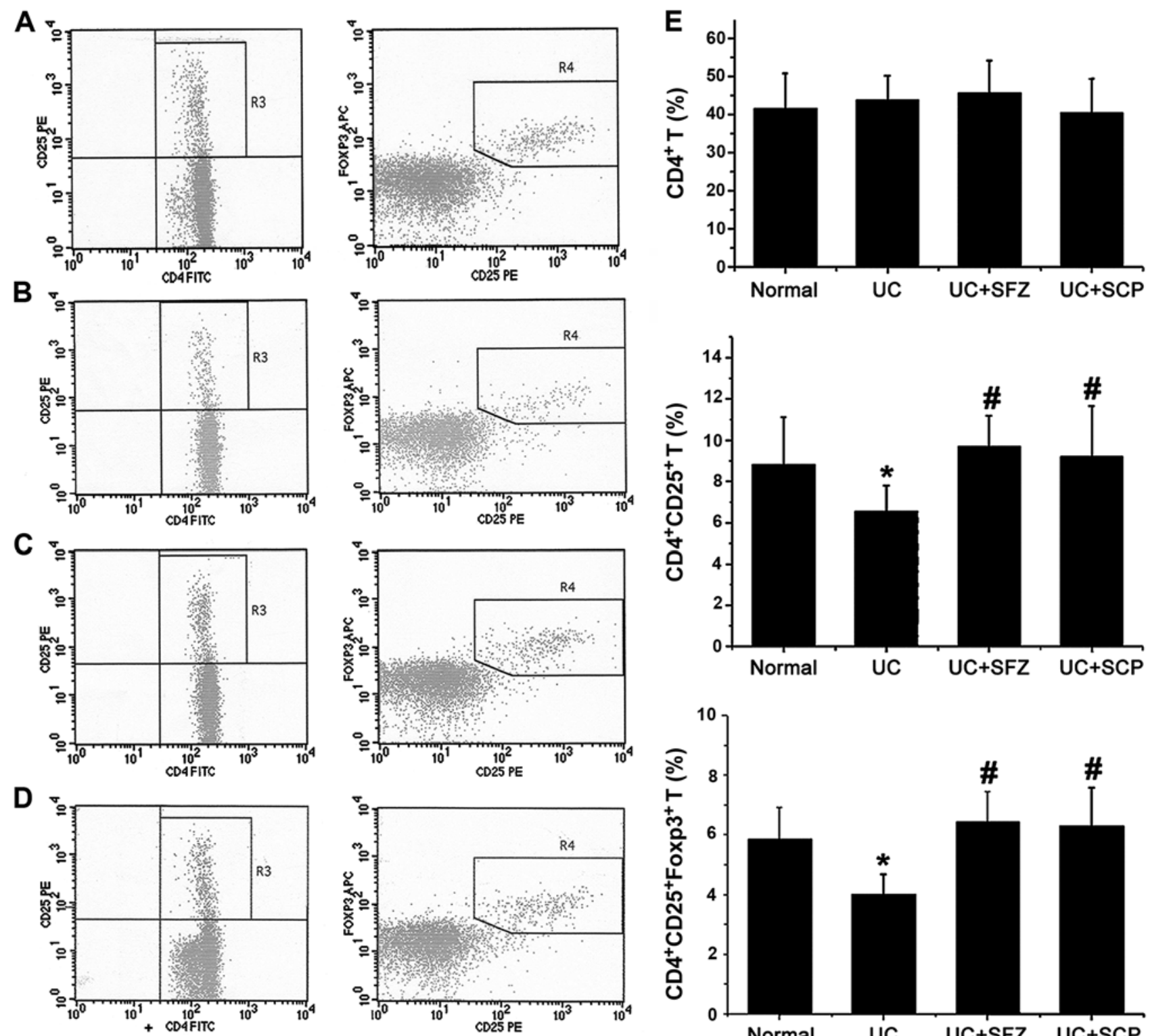

R3: CD4 ${ }^{+}$CD25 $^{+}$T cells; R4: CD4 ${ }^{+}$CD25 $^{+}$Foxp3 $^{+}$Tregs
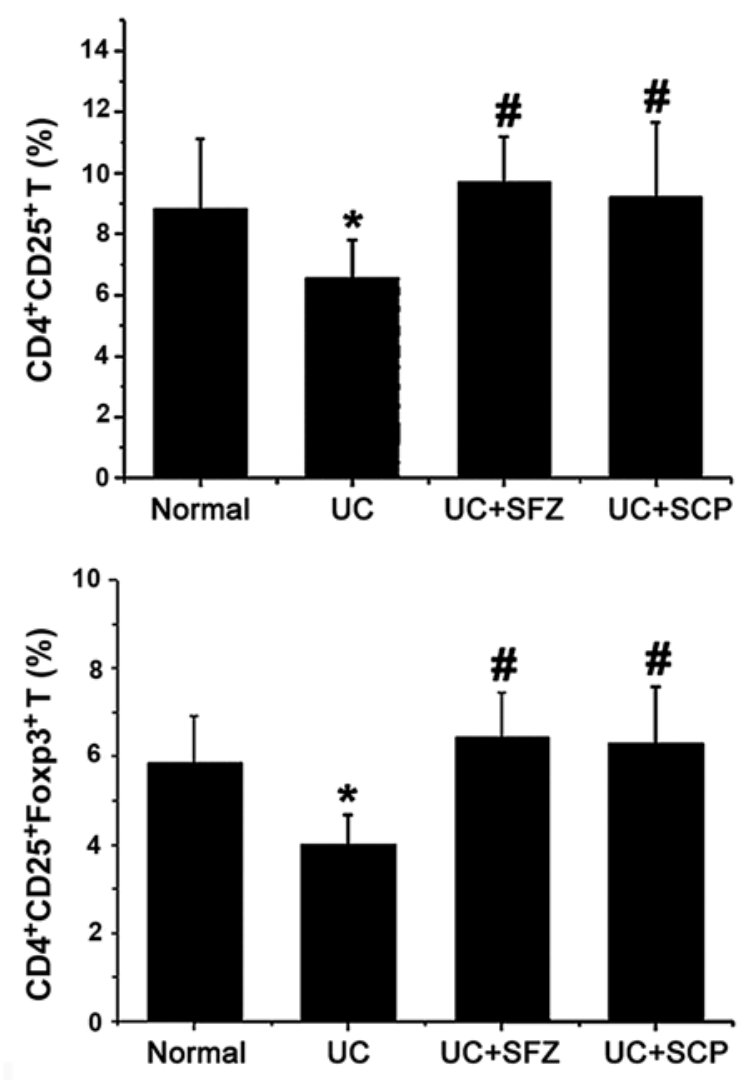

Figure 1. Effect of Semen Crotonis Pulveratum (SCP) on the proportion of $\mathrm{CD} 4^{+} \mathrm{CD} 25^{+} \mathrm{T}$ cells and $\mathrm{CD} 4^{+} \mathrm{CD} 25^{+} \mathrm{Foxp} 3^{+}$Tregs in the peripheral blood of rats with trinitrobenzene sulphonic acid (TNBS)-induced colitis. The proportion of $\mathrm{CD} 4{ }^{+} \mathrm{CD} 25^{+} \mathrm{T}$ cells and $\mathrm{CD} 4^{+} \mathrm{CD} 25^{+} \mathrm{Foxp} 3^{+}$Tregs was analyzed by flow cytometric analysis. (A) Normal control group; (B) ulcerative colitis (UC) model group; (C) UC + sulfasalazine (SFZ) group as a positive control; (D) UC + SCP group; and (E) quantification of the proportion of $\mathrm{CD} 4{ }^{+} \mathrm{CD} 25^{+} \mathrm{T}$ cells and $\mathrm{CD} 4{ }^{+} \mathrm{CD} 25^{+} \mathrm{Foxp} 3^{+}$Tregs in peripheral blood. The data are shown as the means \pm standard deviation (SD) ( $\mathrm{n}=9$ each group). ${ }^{*} \mathrm{P}<0.05$ vs. normal control group; ${ }^{\mathrm{P}} \mathrm{P}<0.05$ vs. $\mathrm{UC}$ model group.

\section{Discussion}

The main aim of the present study was to explore the preliminary mechanisms of action of SCP in the treatment of UC. UC is a chronic inflammatory disease localized to the large intestinal mucosa (26). The etiology of UC remains unknown; however, an association with local immune reactions and intestinal cell apoptosis has been suggested (27). The findings of the present study confirm that the local immune reactions play an important role in UC. There are significant changes in the frequency of circulating $\mathrm{CD} 4{ }^{+} \mathrm{CD} 25^{+} \mathrm{T}$ cells and $\mathrm{CD} 4{ }^{+} \mathrm{CD} 25^{+} \mathrm{Foxp} 3^{+}$ Tregs (28). As previously demonstrated, the production of cytokines by T cells is altered in UC and there is an increase in the production of pro-inflammatory cytokines and a decrease in suppressive cytokines (8). UC is also characterized by epithelial barrier dysfunction due to epithelial cell apoptosis (29).

In this study, the rat model of UC was induced by TNBS. $\mathrm{CD} 4{ }^{+} \mathrm{CD} 25^{+} \mathrm{T}$ cells play a critical role by actively suppressing the immune system and preventing pathological self-reactivity, i.e., autoimmune disease. It is considered that $\mathrm{CD} 4^{+}$triggering plays an essential role in the control of the pathology in patients with UC and a net influx of these cells from the circulation into the mucosa may suppress inflammation (30). In the present study, it was found that the proportion of circulating $\mathrm{CD} 4^{+} \mathrm{CD} 25^{+} \mathrm{T}$ cells was significantly decreased in the rats with UC. On day 7 following the administration of SCP, the level of circulating $\mathrm{CD} 4{ }^{+} \mathrm{CD} 25^{+} \mathrm{T}$ cells was significantly increased. $\mathrm{CD} 4{ }^{+} \mathrm{CD} 25^{+} \mathrm{Foxp}^{+}$Tregs have been shown to suppress $\mathrm{T}$ cell 

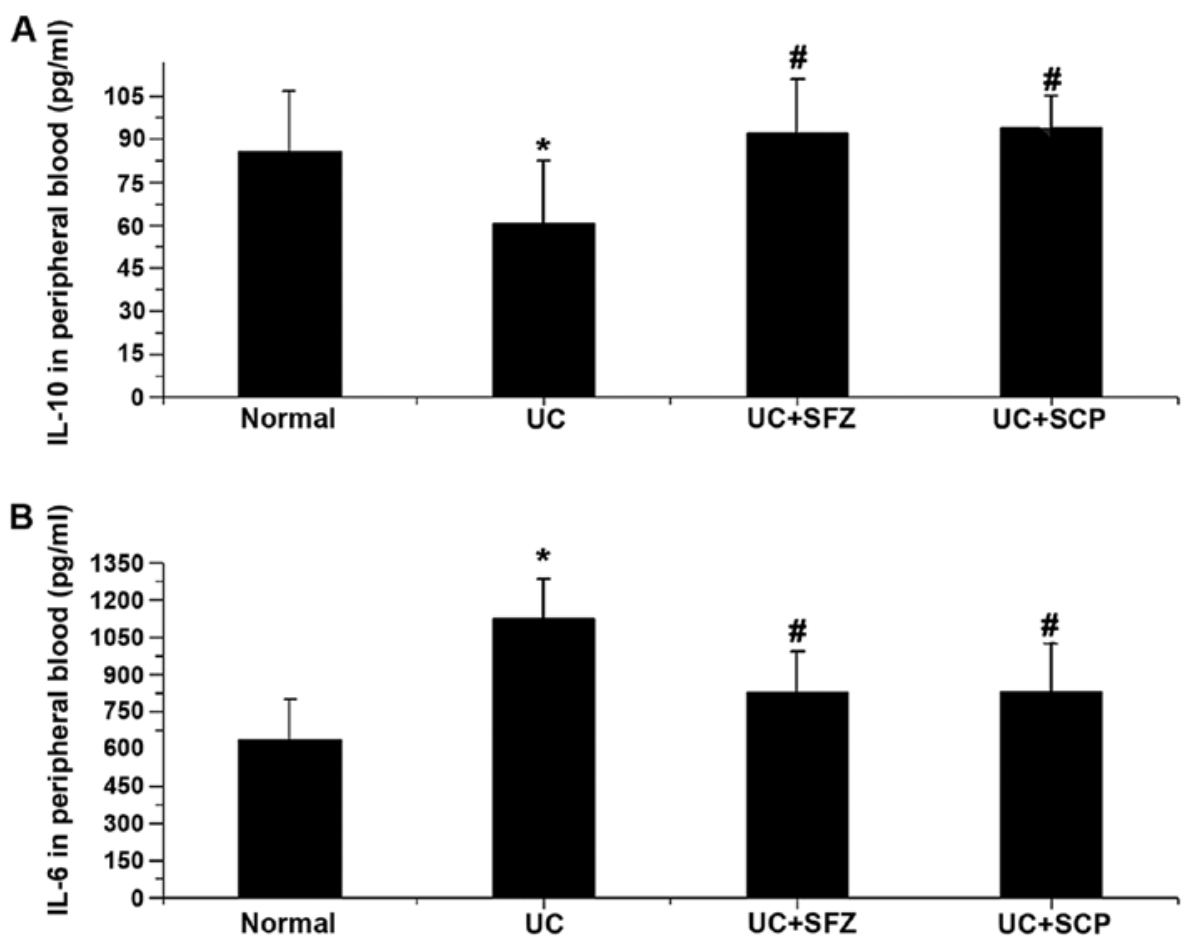

Figure 2. Effect of Semen Crotonis Pulveratum (SCP) on the levels of interleukin (IL)-6 and IL-10 in the peripheral blood of rats with trinitrobenzene sulphonic acid (TNBS)-induced colitis. The levels of (A) IL-10 and (B) IL-6 were determined by ELISA. The data are shown as the means \pm SD ( $n=9$ each group). ${ }^{*} \mathrm{P}<0.05$ vs. normal control group; ${ }^{\#} \mathrm{P}<0.05$ vs. ulcerative colitis (UC) model group.
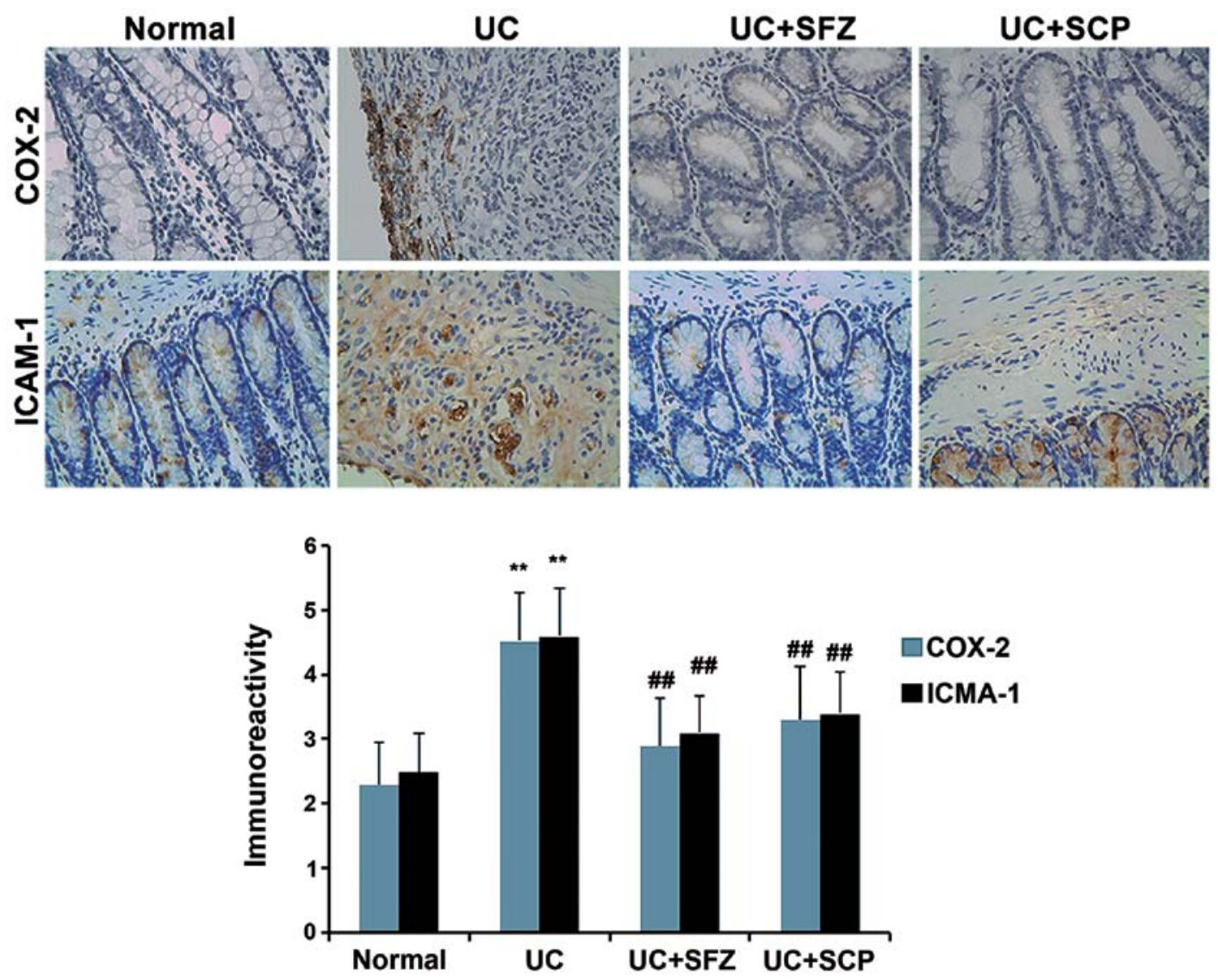

Figure 3. Semen Crotonis Pulveratum (SCP) suppresses the expression of cyclooxygenase-2 (COX-2) and intercellular adhesion molecule-1 (ICAM-1) in colon tissues of rats with trinitrobenzene sulphonic acid (TNBS)-induced colitis. The expression levels of COX-2 and ICAM-1 in colon tissues were determined using immunohistochemical staining (magnification, $\mathrm{x} 400$ ). The data are shown as the means $\pm \mathrm{SD}$ ( $\mathrm{n}=9$ each group). ${ }^{* *} \mathrm{P}<0.01 \mathrm{vs.}$ normal control group; ${ }^{\# \#} \mathrm{P}<0.01 \mathrm{vs}$. ulcerative colitis (UC) model group. 

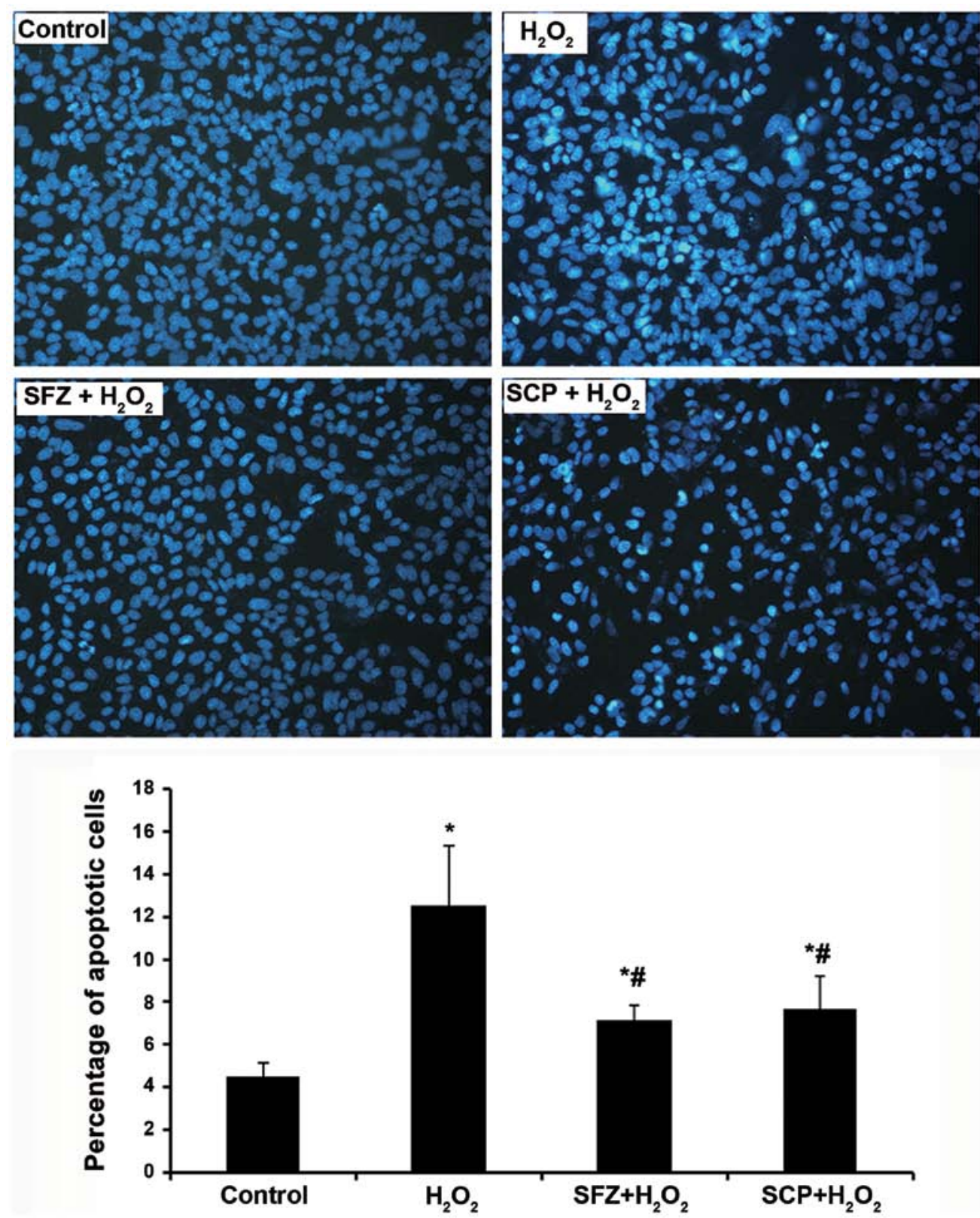

Figure 4. Semen Crotonis Pulveratum (SCP) inhibits the $\mathrm{H}_{2} \mathrm{O}_{2}$ induced intestinal epithelial (IEC-6) cell apoptosis. IEC-6 cells were treated with sulfasalazine (SFZ; $1.6 \mathrm{mg} / \mathrm{ml})$ and SCP $(0.25 \mathrm{mg} / \mathrm{ml})$ for $24 \mathrm{~h}$ and then incubated with $\mathrm{H}_{2} \mathrm{O}_{2}(200 \mu 1 / 1)$ to induce apoptosis. Cell apoptosis was determined by TUNEL assay. (A) Control group (untreated IEC-6 cells); (B) $\mathrm{H}_{2} \mathrm{O}_{2}$ treatment group; (C) SFZ pre-treatment plus $\mathrm{H}_{2} \mathrm{O}_{2}$ group as a positive control; (D) SCP pre-treatment plus $\mathrm{H}_{2} \mathrm{O}_{2}$ group; and (E) quantification of the percentage of apoptotic cells. The data are shown as the means $\pm \mathrm{SD}$. " $\mathrm{P}<0.05$ vs. control group; ${ }^{*} \mathrm{P}<0.05$ vs. $\mathrm{H}_{2} \mathrm{O}_{2}$ treatment group (magnification, $\mathrm{x} 400$ ).

proliferation and experimental autoimmune diseases (28). Additionally, in this study, the level of circulating $\mathrm{CD} 4{ }^{+} \mathrm{CD} 25^{+}$ $\mathrm{T}$ cells and $\mathrm{CD} 4^{+} \mathrm{CD} 25^{+} \mathrm{Foxp} 3^{+}$Tregs shared a similar profile following treatment with SCP, while no significant difference was observed between the SCP and SFZ positive control groups. These findings suggest that treatment with SCP contributes to the counterbalance of mucosal inflammation in patients with UC by increasing the proportion of circulating Tregs.

Normally, COX-2 expression levels are very minimal in the majority of cells; however, COX-2 expression levels are elevated during inflammation (31). A recent study demonstrated that prostaglandins (particularly PGE2), metabolites of the COX-2 pathway, contribute to the pain and swelling associated with inflammation (32). This enzyme is also involved in the indirect production of free radicals and angiogenesis, and thus promotes the local accumulation of lymphocytes and pro-inflammatory cytokines, leading to increased inflammation (33). In this study, treatment with SCP reduced the UC-induced production of COX-2 and ICAM-1 and ultimately inhibited inflammation. These results indicate that SCP inhibits local inflammation of the colon and thus promotes the repair of the mucosal layer.

In a previous study, TNBS-induced colitis was shown to induce a significant increase in myeloperoxidase (MPO) activity and malondialdehyde (MDA) levels and a decrease in glutathione levels in the colon tissue compared to the controls. Additionally, an increase in pro-apoptotic Bax expression and 
A

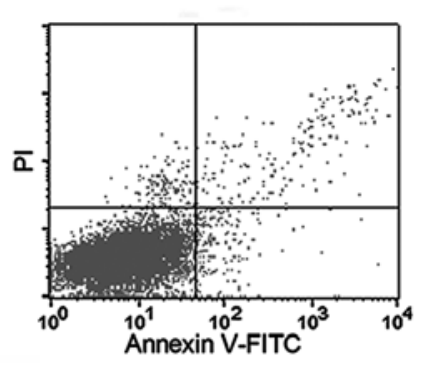

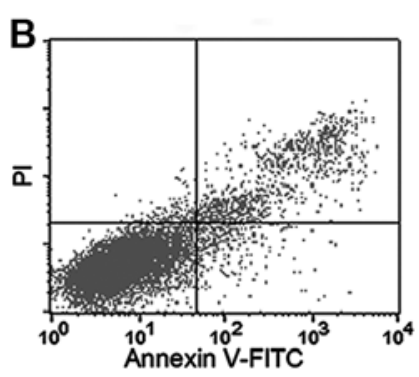

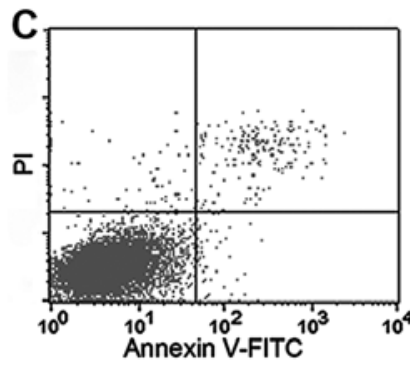

D

E
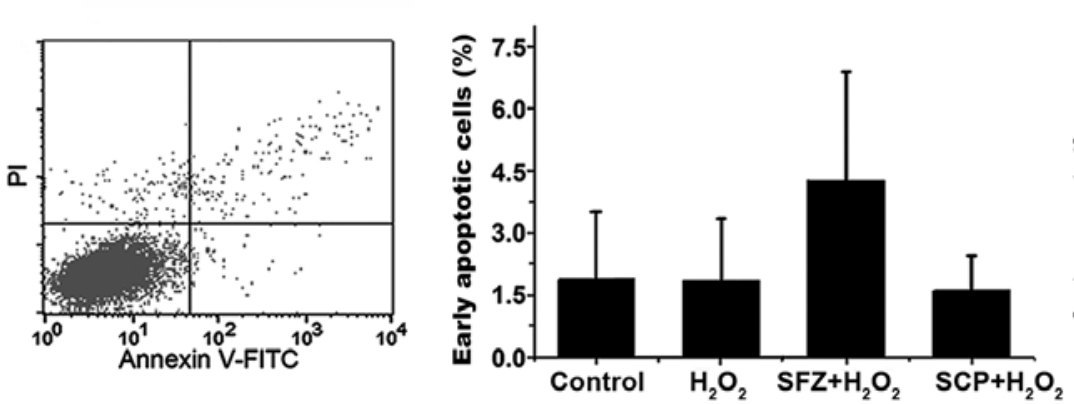

$\mathbf{F}$

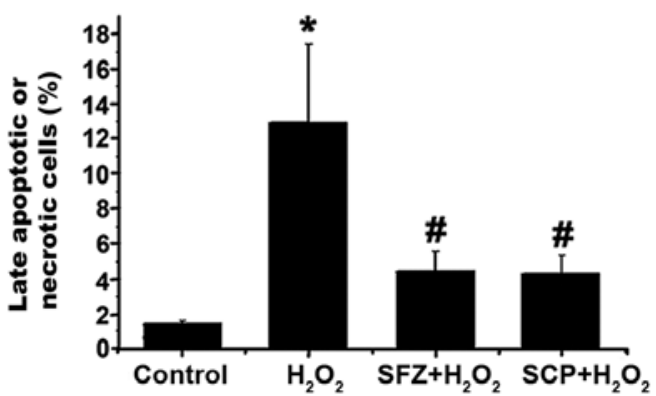

Figure 5. Semen Crotonis Pulveratum (SCP) inhibited $\mathrm{H}_{2} \mathrm{O}_{2}$ induced intestinal epithelial (IEC-6) cell apoptosis. Cell apoptosis was determined by flow cytometry using Annexin V/PI staining. (A) Control group (untreated IEC-6 cells); (B) $\mathrm{H}_{2} \mathrm{O}_{2}$ treatment group; (C) sulfasalazine (SFZ) pre-treatment plus $\mathrm{H}_{2} \mathrm{O}_{2}$ group as positive control; (D) SCP pre-treatment plus $\mathrm{H}_{2} \mathrm{O}_{2}$ group. The viable population is shown in the lower-left quadrant (low-PI and low-FITC signals), the early apoptotic population is shown in the lower-right quadrant (low-PI and high-FITC signals), mechanically damaged cells are shown in the upper-left quadrant (high-PI and low-FITC signals) and the late apoptotic or necrotic population is shown in the upper-right quadrant (high-PI and high-FITC signals). (E) Quantification of the percentage of early-apoptotic cells; and (F) quantification of percentage of late-apoptotic/necrotic cells. The data are shown as the means $\pm \mathrm{SD}$. $\mathrm{P}<0.05 \mathrm{vs}$. control group; ${ }^{\mathrm{P}} \mathrm{P}<0.05$ vs. $\mathrm{H}_{2} \mathrm{O}_{2}$ treatment group.
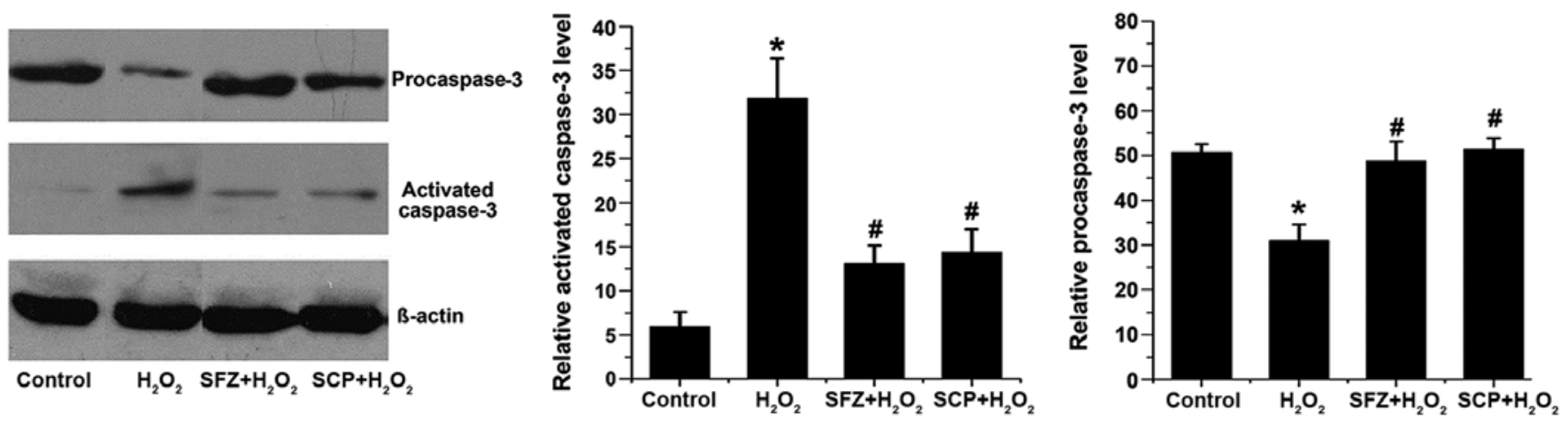

Figure 6. Semen Crotonis Pulveratum (SCP) inhibits the activation of caspase-3 induced by $\mathrm{H}_{2} \mathrm{O}_{2}$ in intestinal epithelial (IEC-6) cells. Activated caspase-3 $(17 / 19 \mathrm{kDa})$ and procaspase-3 $(34 \mathrm{kDa})$ were determined by western blot analysis. The data are shown as the means $\pm \mathrm{SD}$. ${ }^{*} \mathrm{P}<0.05$ vs. control; ${ }^{\text {\# }} \mathrm{P}<0.05$ vs. $\mathrm{H}_{2} \mathrm{O}_{2}$ treatment group.

a decrease in anti-apoptotic B cell lymphoma-2 expression was detected in the colons of rats with TNBS-induced colitis (34). Similarly, in another study, TNBS-induced colitis caused a significant increase in the levels of MDA and MPO, a decrease in superoxide dismutase levels and a decrease in IL-4 and IL-10 mRNA expression levels in rat colon tissues (10).

An elevated expression of S100A9 in colonic epithelial cells mediated by the IL-6/STAT3 signaling cascade may play an important role in the development of colitis (35). In the present study, the enhanced production of IL- 6 and the decreased production of IL-10 in peripheral blood was observed in the rats with UC. These findings confirmed that UC was associated with the imbalanced production of cytokines. In the present study, we also observed the significant downregulation of circulating IL-6 and the upregulation of circulating IL-10 levels following treatment with SCP, and there were no significant differences observed among the SCP and SFZ groups. These results indicate that the protective effects of SCP on UC may be medicated by correcting balance in the production of inflammatory cytokines.

In patients with UC, intestinal epithelial cell apoptosis contributes to the development of UC and apoptotic cell bodies have been found in routine histopathological samples (36). In this study, the $\mathrm{H}_{2} \mathrm{O}_{2}$-induced apoptosis of IEC- 6 cells was used to simulate the apoptosis of intestinal epithelial cells in patients with UC. TUNEL assay is a common method for detecting 
deoxyribonucleic acid (DNA) fragmentation that results from apoptotic signaling cascades (37). The use of this assay relies on the presence of nicks in the DNA that can be identified by terminal deoxynucleotidyl transferase, an enzyme that catalyzes the addition of dUTPs that are secondarily labeled with a marker. Annexin $\mathrm{V}$ is used as a probe to detect cells that have phosphatidylserine (PS) exposed on the surface, an early event found in cell apoptosis $(38,39)$. PI is used as a probe to detect cells with high membrane permeability, a later event found in apoptosis or necrosis $(40,41)$. Caspase- 3 is activated in apoptotic cells through both extrinsic and intrinsic pathways. As an executioner caspase, procaspase-3 $(34 \mathrm{kDa})$ has virtually no activity until it is cleaved by initiator caspases after apoptotic signaling events are triggered (42). In this study, following treatment with $\mathrm{H}_{2} \mathrm{O}_{2}$, typical apoptotic cells were detected by both TUNEL assay and flow cytometry using Annexin V/PI staining. Furthermore, an elevated level of activated caspase-3 $(17 / 19 \mathrm{kDa})$ was observed by western blot analysis. Treatment with SCP significantly decreased the number of apoptotic cells and the activation of caspase- 3 . These results suggest that treatment with SCP inhibits the activation of caspase-3 and suppresses the apoptosis of IEC- 6 cells. However, further studies are warranted in this field in order to obtain a better understanding of the specific signal transduction pathways of these drugs.

In conclusion, our results demonstrate that $\mathrm{SCP}$ inhibits inflammation in UC by increasing the proportion of circulating Tregs, altering cytokine production and decreasing COX-2 and ICAM-1 expression. In addition, it protects against $\mathrm{H}_{2} \mathrm{O}_{2}-$ induced intestinal cell apoptosis in vitro.

\section{Acknowledgements}

The present study was supported by the Tianjing Science and Technology Innovation Fund (06FZZDSH00405).

\section{References}

1. Burisch J, Pedersen N, Čuković-Čavka S, et al: EpiCom-group: East-West gradient in the incidence of inflammatory bowel disease in Europe: The ECCO-EpiCom inception cohort. Gut 63: 588-597, 2014.

2. Radwan P, Radwan-Kwiatek K, Tabarkiewicz J, Radej S and Rolinski J: Enhanced phenotypic and functional maturation of monocyte-derived dendritic cells from patients with active Crohn's disease and ulcerative colitis. J Physiol Pharmacol 61: 695-703, 2010.

3. Zhao QJ, Yu YB, Zuo XL, Dong YY and Li YQ: Milk fat globuleepidermal growth factor 8 is decreased in intestinal epithelium of ulcerative colitis patients and thereby causes increased apoptosis and impaired wound healing. Mol Med 18: 497-506, 2012.

4. Serrano D, Bhowmick T, Chadha R, Garnacho C and Muro S: Intercellular adhesion molecule 1 engagement modulates sphingomyelinase and ceramide, supporting uptake of drug carriers by the vascular endothelium. Arterioscler Thromb Vasc Biol 32: 1178-1185, 2012.

5. Kim YJ, Lee JS, Hong KS, Chung JW, Kim JH and Hahm KB: Novel application of proton pump inhibitor for the prevention of colitis-induced colorectal carcinogenesis beyond acid suppression. Cancer Prev Res (Phila) 3: 963-974, 2010.

6. Flannigan KL, Agbor TA, Blackler RW, et al: Impaired hydrogen sulfide synthesis and IL-10 signaling underlie hyperhomocysteinemia-associated exacerbation of colitis. Proc Natl Acad Sci USA 111: 13559-13564, 2014.

7. Yu QT, Saruta M, Avanesyan A, Fleshner PR, Banham AH and Papadakis KA: Expression and functional characterization of $\mathrm{FOXP}^{+} \mathrm{CD}^{+}$regulatory $\mathrm{T}$ cells in ulcerative colitis. Inflamm Bowel Dis 13: 191-199, 2007.
8. Imaoka A, Shima T, Kato K, Mizuno S, Uehara T, Matsumoto S, Setoyama H, Hara T and Umesaki Y: Anti-inflammatory activity of probiotic Bifidobacterium: Enhancement of IL-10 production in peripheral blood mononuclear cells from ulcerative colitis patients and inhibition of IL-8 secretion in HT-29 cells. World J Gastroenterol 14: 2511-2516, 2008.

9. Chen X: Protective effects of quercetin on liver injury induced by ethanol. Pharmacogn Mag 6: 135-141, 2010.

10. Liu DY, Guan YM, Zhao HM, Yan DM, Tong WT, Wan PT, Zhu WF, Liu HN and Liang XL: The protective and healing effects of Si Shen Wan in trinitrobenzene sulphonic acid-induced colitis. J Ethnopharmacol 143: 435-440, 2012.

11. Lindsay JO and Hodgson HJ: Review article: The immunoregulatory cytokine interleukin-10 - a therapy for Crohn's disease. Aliment Pharmacol Ther 15: 1709-1716, 2001.

12. Kim SJ, Kim YG, Kim DS, et al: Oldenlandia diffusa ameliorates dextran sulphate sodium-induced colitis through inhibition of NF- $\kappa$ B activation. Am J Chin Med 39: 957-969, 2011.

13. Heinrich PC, Behrmann I, Müller-Newen G, Schaper F and Graeve L: Interleukin-6-type cytokine signalling through the gp130/Jak/STAT pathway. Biochem J 334: 297-314, 1998.

14. Gracie DJ and Ford AC: Evidence-based management of ulcerative colitis. Minerva Gastroenterol Dietol 58: 87-99, 2012.

15. Ford AC, Bernstein CN, Khan KJ, Abreu MT, Marshall JK, Talley NJ and Moayyedi P: Glucocorticosteroid therapy in inflammatory bowel disease: Systematic review and metaanalysis. Am J Gastroenterol 106: 590-599, 2011.

16. Prantera $\mathrm{C}$ and Marconi S: Glucocorticosteroids in the treatment of inflammatory bowel disease and approaches to minimizing systemic activity. Therap Adv Gastroenterol 6: 137-156, 2013.

17. Oz HS, Chen T and de Villiers WJ: Green tea polyphenols and sulfasalazine have parallel anti-inflammatory properties in colitis models. Front Immunol 4: 132, 2013.

18. Margagnoni G, Pagnini C, Menasci F, Festa S and Delle Fave G: Critical review of the evidence on 5-aminosalicilate for chemoprevention of colorectal cancer in ulcerative colitis: A methodological question. Curr Clin Pharmacol 9: 84-90, 2014.

19. Watson S, Pensabene L, Mitchell P and Bousvaros A: Outcomes and adverse events in children and young adults undergoing tacrolimus therapy for steroid-refractory colitis. Inflamm Bowel Dis 17: 22-29, 2011.

20. Kruis W, Schreiber S, Theuer D, et al: Low dose balsalazide (1.5 g twice daily) and mesalazine (0.5 g three times daily) maintained remission of ulcerative colitis but high dose balsalazide $(3.0 \mathrm{~g}$ twice daily) was superior in preventing relapses. Gut 49: 783-789, 2001.

21. Minaiyana M, Ghannadib A, Mahzounic P and Jaffari-Shirazid E: Comparative study of Berberis vulgaris fruit extract and berberine chloride effects on acetic acid-induced colitis in rats. Iran J Pharm Res 10: 97-104, 2010.

22. Atyabi F, Vahabzadeh R and Dinarvand R: Preparation of ethylcellulose coated gelatin microspheres as a multiparticulate colonic delivery system for 5-aminosalicilic acid. Iran J Pharm Res 2: 81-86, 2004.

23. Zhang J, Gao W, Hu X, Liu Z and Liu C: The influence of compatibility of traditional Chinese medicine on the pharmacokinetic of main components in Fructus aurantii. J Ethnopharmacol 144: 277-283, 2012.

24. Chinese Pharmacopoeia Commission: Chinese Pharmacopoeia Commission. Pharmacopoeia of the People's Republic of China. Chemical Industry Press, Beijing, 2005.

25. Liu DY, Zhao HM, Zhao N, Xin ZP and Lu AP: Pharmacological effects of ba-wei-xi-lei powder on ulcerative colitis in rats with enema application. Am J Chin Med 34: 461-469, 2006.

26. Vilela EG, Torres HO, Martins FP, Ferrari ML, Andrade MM and Cunha AS: Evaluation of inflammatory activity in Crohn's disease and ulcerative colitis. World J Gastroenterol 18: 872-881, 2012.

27. Ślebioda TJ and Kmieć Z: Tumour necrosis factor superfamily members in the pathogenesis of inflammatory bowel disease. Mediators Inflamm 2014: 325129, 2014.

28. Boschetti G, Nancey S, Sardi F, Roblin X, Flourié B and Kaiserlian D: Therapy with anti-TNF $\alpha$ antibody enhances number and function of Foxp3(+) regulatory T cells in inflammatory bowel diseases. Inflamm Bowel Dis 17: 160-170, 2011.

29. Heller F, Florian P, Bojarski C, Richter J, Christ M, Hillenbrand B, Mankertz J, Gitter A, Burgel N and Fromm M: Interleukin-13 is the key effector Th2 cytokine in ulcerative colitis that affects epithelial tight junctions, apoptosis, and cell restitution. Gastroenterology 129: 550-564, 2005. 
30. Kamikozuru K, Fukunaga K, Hirota S, et al: The expression profile of functional regulatory $\mathrm{T}$ cells, $\mathrm{CD} 4{ }^{+} \mathrm{CD} 25^{\text {hight }} /$ forkhead box protein $\mathrm{P}^{+}$, in patients with ulcerative colitis during active and quiescent disease. Clin Exp Immunol 156: 320-327, 2009.

31. Flower RJ: Drugs which inhibit prostaglandin biosynthesis. Pharmacol Rev 26: 33-67, 1974.

32. Kim DS, Kim SJ, Kim MC, Jeon YD, Um JY and Hong SH: The therapeutic effect of chelidonic acid on ulcerative colitis. Biol Pharm Bull 35: 666-671, 2012.

33. Talero E, Sánchez-Fidalgo S, Villegas I, de la Lastra CA Illanes $\mathrm{M}$ and Motilva V: Role of different inflammatory and tumor biomarkers in the development of ulcerative colitisassociated carcinogenesis. Inflamm Bowel Dis 17: 696-710, 2011.

34. Giriş M, Depboylu B, Doğru-Abbasoğlu S, Erbil Y, Olgaç V, Aliş H, Aykaç-Toker $\mathrm{G}$ and Uysal M: Effect of taurine on oxidative stress and apoptosis-related protein expression in trinitrobenzene sulphonic acid-induced colitis. Clin Exp Immunol 152: 102-110, 2008.

35. Lee MJ, Lee JK, Choi JW, et al: Interleukin-6 induces S100A9 expression in colonic epithelial cells through STAT3 activation in experimental ulcerative colitis. PLoS One 7: e38801, 2012.

36. Qiu W, Wu B, Wang X, Buchanan ME, Regueiro MD Hartman DJ, Schoen RE, Yu J and Zhang L: PUMA-mediated intestinal epithelial apoptosis contributes to ulcerative colitis in humans and mice. J Clin Invest 121: 1722-1732, 2011.
37. Negoescu A, Guillermet C, Lorimier P, Brambilla E and Labat-Moleur F: Importance of DNA fragmentation in apoptosis with regard to TUNEL specificity. Biomed Pharmacother 52: 252-258, 1998.

38. Vermes I, Haanen C, Steffens-Nakken H and Reutelingsperger C A novel assay for apoptosis. Flow cytometric detection of phosphatidylserine expression on early apoptotic cells using fluorescein labelled Annexin V. J Immunol Methods 184: 39-51, 1995.

39. Samarghandian S, Afshari JT and Davoodi S: Honey induces apoptosis in renal cell carcinoma. Pharmacogn Mag 7: 46-52, 2011.

40. Lecoeur H: Nuclear apoptosis detection by flow cytometry: Influence of endogenous endonucleases. Exp Cell Res 277: 1-14, 2002.

41. Yu JZ, Wu XL, Yu B, Dai CQ, Liu KL, Guo-Qiang Q, Zhou GX, $\mathrm{Lu} \mathrm{SH}, \mathrm{Ju} \mathrm{H}$ and Chen XY: The suppression effects of desacetyluvaricin on hepatocellular carcinoma and its possible mechanism. Pharmacogn Mag 8: 225-230, 2012.

42. Walters J, Pop C, Scott FL, Drag M, Swartz P, Mattos C, Salvesen GS and Clark AC: A constitutively active and uninhibitable caspase-3 zymogen efficiently induces apoptosis. Biochem J 424: 335-345, 2009. 